\title{
Metathesis and Decomposition of Fischer Carbenes of Cyclometalated Z-Selective Ruthenium Metathesis Catalysts
}

Tonia S. Ahmed, ${ }^{\dagger, \S}$ Jessica M. Grandner, ${ }^{\ddagger}, \S$ Buck L. H. Taylor, ${ }^{\ddagger}$ Myles B. Herbert, ${ }^{\dagger}$ K. N. Houk, ${ }^{*}{ }^{\ddagger}$ (อ) and Robert H. Grubbs* ${ }^{*}+(1$

\begin{abstract}
${ }^{\dagger}$ Arnold and Mabel Beckman Laboratory of Chemical Synthesis, Division of Chemistry and Chemical Engineering, California Institute of Technology, Pasadena, California 91125, United States

${ }^{\ddagger}$ Department of Chemistry and Biochemistry, University of California, Los Angeles, California 90095, United States
\end{abstract}

\section{Supporting Information}

ABSTRACT: The addition of vinyl ethers to Z-selective, cyclometalated ruthenium metathesis catalysts generates Fischer carbene complexes. Although Fischer carbenes are usually thought to be metathesis inactive, we show that Fischer carbenes are metathesis active under certain circumstances. These species were found to decompose facilely to $\mathrm{Ru}$ hydride complexes, as identified by both experiment and computation. Since vinyl ethers are often used to quench metathesis reactions implementing Ru-based metathesis catalysts, their decomposition to hydrides can have a deleterious effect on the desired stereochemistry of the olefin product.

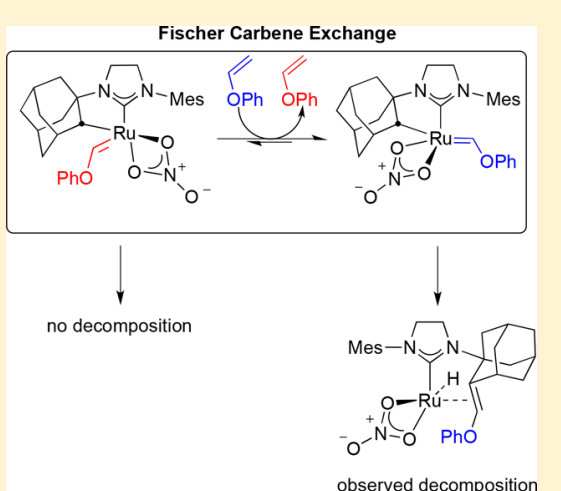

$\mathrm{O}$ lefin metathesis has become a favored method for the generation of carbon-carbon double bonds and has been implemented in countless fields, including green chemistry, ${ }^{1}$ organic synthesis, ${ }^{2}$ materials science, ${ }^{3}$ and pharmaceuticals. ${ }^{4}$ Ruthenium-based catalysts used for this transformation exhibit excellent stability, functional group tolerance, and general ease of use. ${ }^{5}$ Reactions utilizing these catalysts are often quenched by the addition of an excess of a vinyl ether. ${ }^{6}$ As an example, ethyl vinyl ether reacts with catalyst 1 to form Fischer carbene ruthenium complex 2 (Scheme 1). ${ }^{7-9}$

Scheme 1. Formation of Fischer Carbene Complexes by Reaction of Ethyl Vinyl Ether with Olefin Metathesis Catalysts

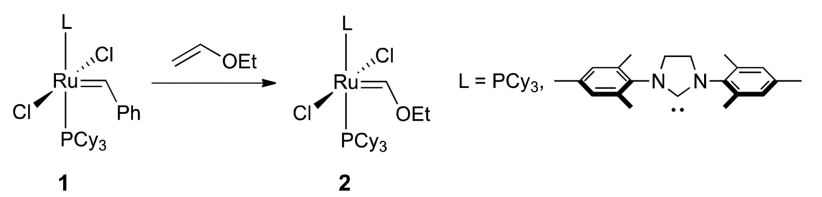

Due to their stabilities, Fischer carbenes are considered metathesis inactive under standard conditions. However, Fischer carbenes have been found to be active at elevated temperatures and with specific substrates. ${ }^{9,10}$ Takahira and Morizawa demonstrated the ability of 2, bearing the 1,3dimesityl-4,5-dihydroimidazol-2-ylidene (SIMes) ligand, to catalyze productive metathesis using heavily fluorinated olefins, albeit with very low catalyst turnover. ${ }^{10}$ The unexpected activity of these ruthenium complexes is due to the relative thermodynamic stability of the fluoro-Fischer carbene formed by metathesis, or Fischer carbene exchange, with 2 .

In 2011, kinetically $Z$ selective ruthenium-based catalysts were reported bearing an adamantyl-chelated NHC ligand and pivalate X-type ligand. ${ }^{11}$ Many analogues have now been synthesized, including the nitrate-substituted, highly active, and $Z$-selective catalysts $3^{12}$ and 4 (Figure 1 ). ${ }^{13}$ Mechanistic and

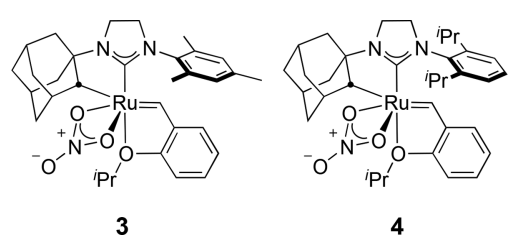

Figure 1. Prominent $Z$-selective catalysts.

decomposition studies of these types of cyclometalated complexes have been carried out by both experiment and theory. ${ }^{14,15}$ Decomposition proceeds via irreversible insertion of the alkylidene into the chelating ruthenium-carbon bond to produce a ruthenium alkyl intermediate (6; Scheme 2). Subsequent $\alpha$-hydride elimination gives 7 , while $\beta$-hydride elimination provides 8 . Both experiment and theory show that $\beta$-hydride elimination from $\mathbf{6}$ to form $\mathbf{8}$ is the preferred

Received: March 10, 2018

Published: July 10, 2018 
Scheme 2. Decomposition Pathway of Cyclometalated Ruthenium Catalyst $5^{a}$

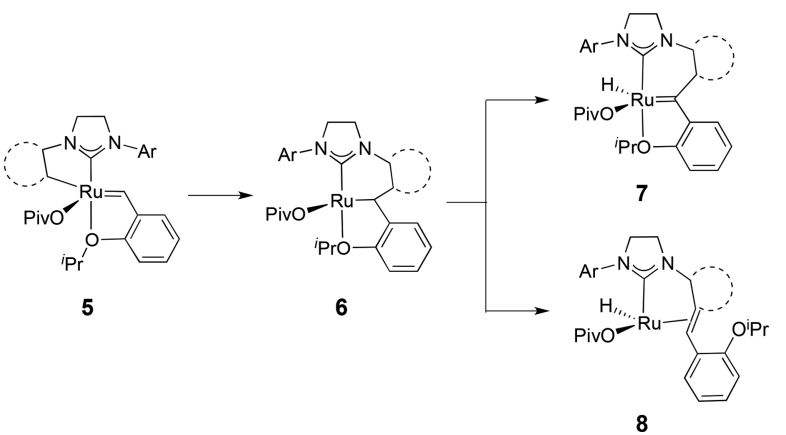

${ }^{a}$ The dashed circle indicates adamantyl or $o$-tolyl; Ar = DIPP or Mes.

mechanistic pathway for the catalyst diastereomeric form of 35. $^{15}$

Because other Ru-based Fischer carbenes have exhibited impressive stability, reactions using these cyclometalated metathesis catalysts are also often quenched by vinyl ethers. ${ }^{16}$ Herein we report reactions of 3 and $\mathbf{4}$ with vinyl ethers and identify a ruthenium hydride decomposition product potentially capable of causing olefin isomerization. ${ }^{17}$ Computations were used to explore the decomposition, and we have found that a metathesis reaction of the Fischer carbene is an integral part of the decomposition pathway.

The reactions of phenyl vinyl ether with chelated catalysts 3 and 4 were performed in THF- $d_{8}$ and monitored using ${ }^{1} \mathrm{H}$ NMR spectroscopy. For each of these catalysts, generation of a species posited to be a Fischer carbene was observed by the appearance of a peak shifted upfield $(\sim 14 \mathrm{ppm})$ with respect to the original alkylidene signal. ${ }^{18}$ Subsequent formation of a $\mathrm{Ru}$ hydride species from each of these complexes was observed by the appearance of ${ }^{1} \mathrm{H}$ NMR signals at -12.16 and -11.97 ppm, respectively (Scheme 3). ${ }^{19}$ Identification of these

Scheme 3. Reactions of Z-Selective Catalysts 3 and 4 with Vinyl Ethers Generating Fischer Carbenes That Decompose Quantitatively to Ru Hydride Complexes As Observed by ${ }^{1} \mathrm{H}$ NMR Spectroscopy in THF- $d_{8}$ Using HMDSO as an Internal Standard

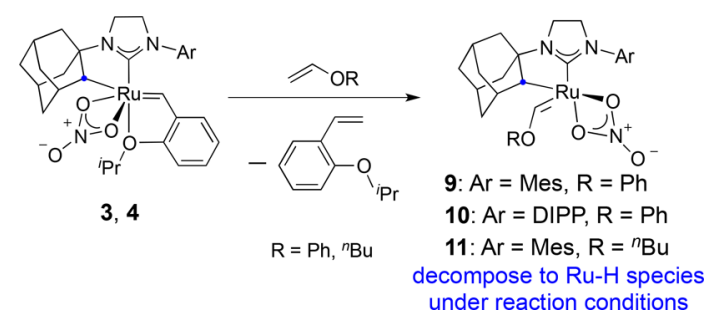

complexes by NMR spectroscopy was challenging due to significant overlap of aromatic ${ }^{1} \mathrm{H}$ and ${ }^{13} \mathrm{C}$ signals derived from phenyl vinyl ether, 2-isopropoxystyrene eliminated by the reaction, and the $\mathrm{N}$-mesityl groups of the NHC ligand of the catalyst. ${ }^{20}$ Consequently, the reaction of butyl vinyl ether with 1 equiv of 3 in THF- $d_{8}$ was studied in order facilitate analysis of the complex by NMR spectroscopy using 1 equiv of HMDSO as an internal standard. The results of this reaction mirrored the observations of the reactions with phenyl vinyl ether. The disappearance of the ${ }^{1} \mathrm{H}$ signal corresponding to the benzylidene proton of $\mathbf{3}$ and the appearance of a broad peak of the proposed Fischer carbene at 13.83 ppm was observed. ${ }^{21}$ The subsequent disappearance of this signal and concurrent appearance of a new signal at $-12.62 \mathrm{ppm}$ indicated the formation of the hydride species in quantitative yield.

Analogous to previously reported decomposition routes of cyclometalated $\mathrm{Ru}$-based $\mathrm{Z}$-selective catalysts, pathways from the Fischer carbene complex to two possible ruthenium hydride complexes were conceivable (Scheme 4). After initial

Scheme 4. Possible Pathways of Decomposition of the Fischer Carbene Complexes under Reaction Conditions To Form Ru Hydride Complex 13 or 14 from Insertion Intermediate 12

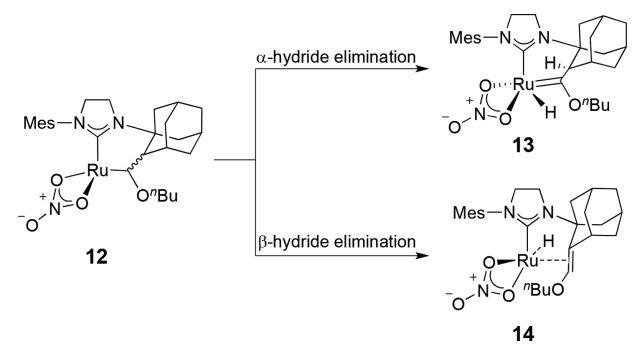

insertion of the alkylidene into the $\mathrm{Ru}$-adamantyl bond to form the ruthenium alkyl species 12, $\alpha$-hydride elimination would generate 13 while a $\beta$-hydride elimination pathway would give product 14 .

In the ${ }^{1} \mathrm{H}$ NMR spectrum of this reaction mixture, a singlet corresponding to a single proton appears at $5.12 \mathrm{ppm}$, consistent with that of the alkene proton of known $\beta$-hydride decomposition products of $Z$-selective catalysts. ${ }^{15}$ Furthermore, a signal characteristic of the carbon of a $\mathrm{Ru}=\mathrm{C}$ bond at around $300 \mathrm{ppm}$ was not observed in the ${ }^{13} \mathrm{C}$ NMR spectrum. ${ }^{22,23}$ These data are consistent with the structure of the $\beta$-hydride elimination product 14 rather than 13 .

To confirm the connectivity and structure of the decomposition product, ${ }^{1} \mathrm{H}-{ }^{13} \mathrm{C}$ HMBC studies were performed and correlations between the methylenes of the butyl group to the aforementioned alkenyl singlet at 5.12 ppm were observed, which furthermore shows correlations with the protons of the adamantyl group. Further supporting this proposed structure, the hydride showed correlations with the alkenyl carbons, the carbene carbon of the NHC, and a methylene carbon of the butyl group in the ${ }^{1} \mathrm{H}-{ }^{13} \mathrm{C}$ HMBC. These correlations are consistent with the structure of $14 .{ }^{13} \mathrm{C}$ DEPT experiments showed the existence of 4 methyl groups, 10 methylene groups, 6 methine groups, and 7 quaternary carbons in the structure of this complex, which agrees with the proposed structure.

Density functional calculations were performed to determine the decomposition pathways available to Fischer carbenes derived from complex $\mathbf{3}$. Reaction of $\mathbf{3}$ with phenyl vinyl ether leads to the formation of Fischer carbene complex 9 (Scheme 5). However, 9 cannot lead to the observed product 15 via migratory insertion and $\beta$-hydride elimination. ${ }^{5}$ Figure 2 is a top view of 9 and the subsequent migratory insertion intermediate 16. The hydrogen on the chelated carbon of 9, highlighted in green in the $3 \mathrm{D}$ images of Figure 2, is on the same side as the Fischer carbene and is far from the ruthenium center. After migratory insertion to $\mathbf{1 6}$, this green $\beta$-hydrogen is pushed even further from the ruthenium center, to a distance of $3.84 \AA$. The highlighted $\beta$-hydrogen is not available for 
Scheme 5. Fischer Carbene Exchange Pathway To Reach the Observed $\beta$-Hydride Elimination Product 15
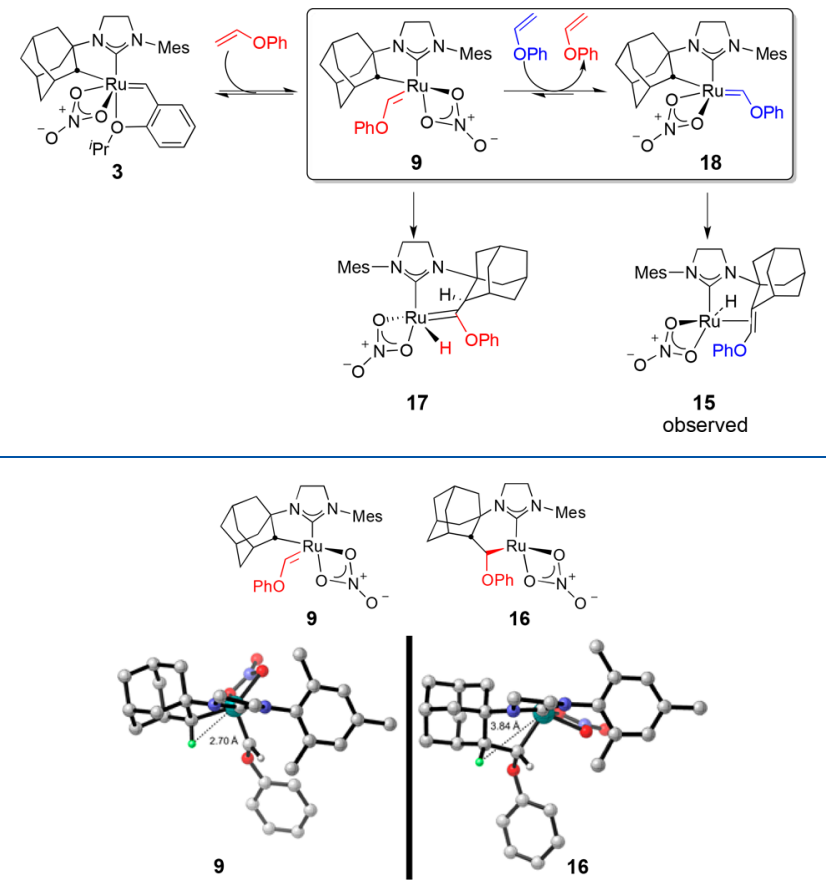

Figure 2. View of 9 and 16, looking down on the NHC. The $\beta$ hydrogen is highlighted in green.

elimination due to this distance and is thus prevented from direct degradation to the observed product 15. DFT results (Figure S18) indicate that migratory insertion followed by rearrangement and $\alpha$-hydride elimination could occur to produce 17 with a rate-determining barrier of $25.5 \mathrm{kcal} / \mathrm{mol}$. However, this product has not been observed experimentally.

Since the calculations showed that 9 could not lead directly to the observed product $\mathbf{1 5}$, there must be an alternative, lower energy path to decomposition of $\mathbf{9}$. On the basis of recent precedent for Fischer carbene exchange, ${ }^{10}$ we propose epimerization of Fischer carbene $\mathbf{9}$ to $\mathbf{1 8}$ via metathesis with excess vinyl ether. ${ }^{24}$ Complex 18 could then decompose to the experimentally observed hydride $\mathbf{1 5}$ via the previously reported pathway shown in Scheme 2.
The free energy surface for Fischer carbene exchange is shown in Figure 3. The $[2+2]$ cycloaddition of 9 with phenyl vinyl ether has a barrier of only $14.2 \mathrm{kcal} / \mathrm{mol}$ to form metallacycle 20. Isomerization of $\mathbf{2 0}$ to 21 followed by retro-[ 2 + 2] via 22-TS leads to diastereomeric Fischer carbene 18. Carbene rotation leads to the more stable conformer $\mathbf{1 8}^{\prime}$. Calculated barriers for the homodimerization of olefins with catalyst 3 and analogues range from $\sim 11$ to $15 \mathrm{kcal} / \mathrm{mol}$ and are comparable to the barrier for Fischer carbene exchange. ${ }^{14,25}$ Metathesis of 9 with vinyl ethers is therefore both kinetically and thermodynamically feasible.

The decomposition pathways of complexes 18 and $18^{\prime}$ were also calculated. Decomposition of $\mathbf{1 8}$ leads to the more thermodynamically stable hydride and is shown in Figure $4{ }^{26}$

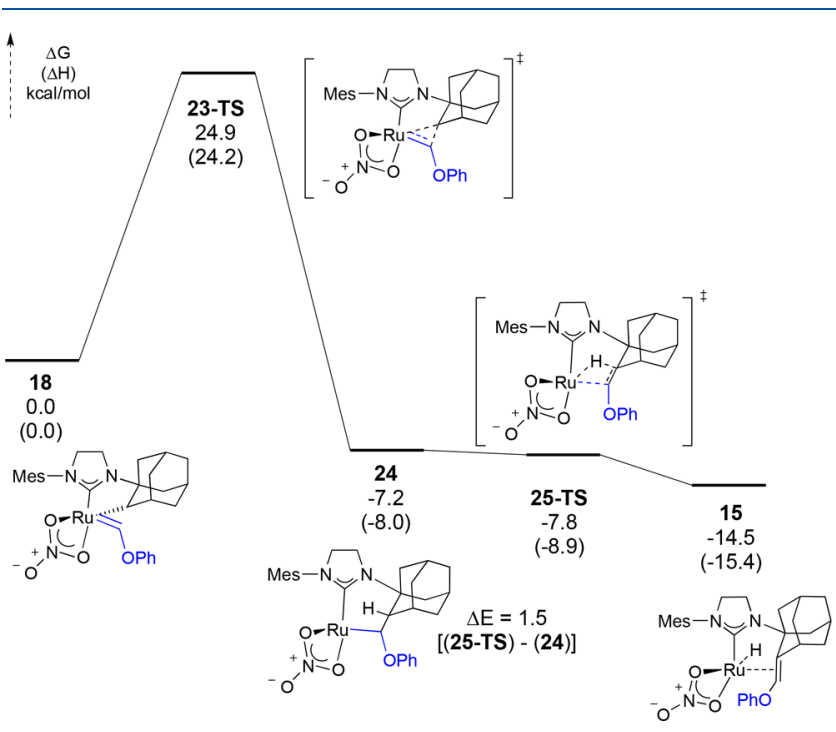

Figure 4. Decomposition of Fischer carbene 18 to hydride 15.

Carbene insertion via 23-TS has a barrier of $25 \mathrm{kcal} / \mathrm{mol}$ from 18. This barrier is slightly lower than that reported for the carbene insertion of catalyst $5 .^{15} \beta$-hydride elimination from 24 is essentially barrierless and leads directly to hydride $\mathbf{1 5}$, with the vinyl ether acting as a chelating $\pi$ ligand.

Reaction of catalyst 3 with 0.1 equiv of butyl vinyl ether in THF- $d_{8}$ leads to quantitative conversion of the butyl vinyl

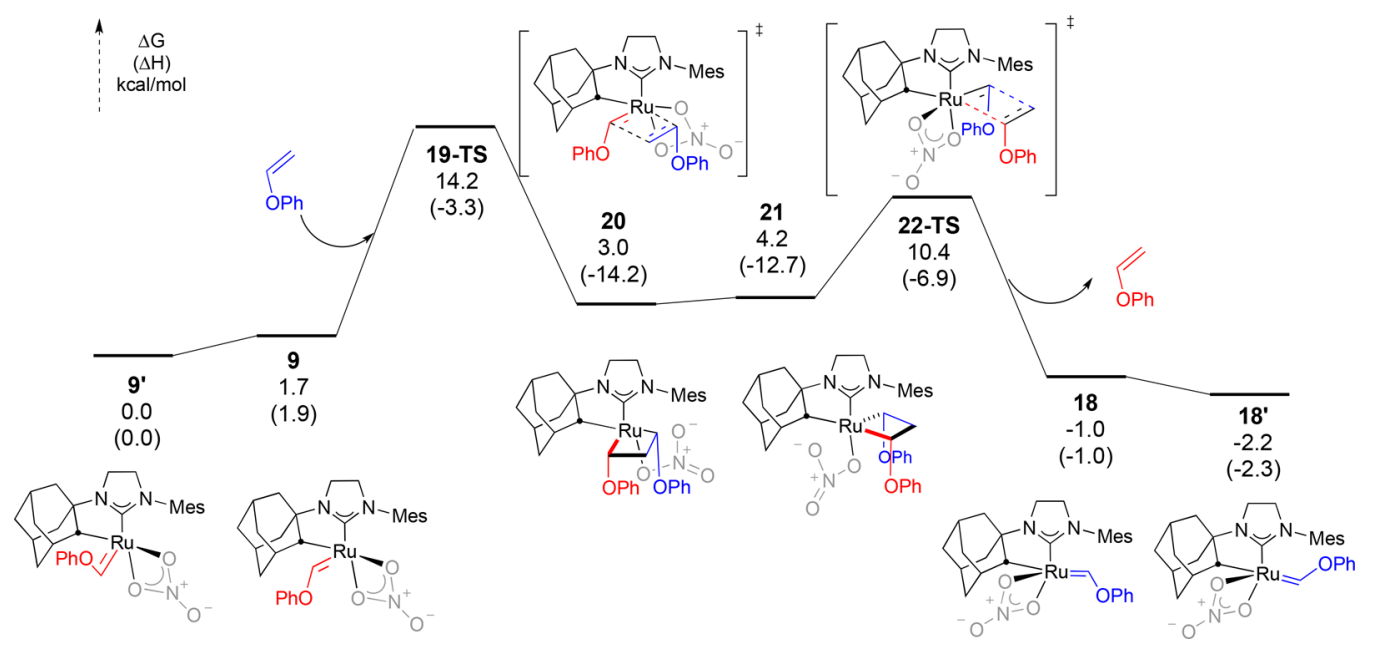

Figure 3. Metathesis of Fischer carbene 9 with phenyl vinyl ether to form the thermodynamically more stable diastereomer $\mathbf{1 8}^{\prime}$. 
ether to $\mathbf{1 5}$ as determined by using 0.1 equiv of HMDSO as an internal standard, indicating that an excess of vinyl ether is not necessary for decomposition. This result is consistent with our predicted metathesis-dependent decomposition pathway as long as catalyst initiation to $\mathbf{9}$ is slower than Fischer carbene exchange from 9 to 18. Wang et al. previously computed initiation of 3 with styrene. The rate-limiting step of the initiation is retro- $[2+2]$ to form the free 2 -isopropoxystyrene. $^{25}$ The computed barrier for this step in the reaction of 3 with phenyl vinyl ether is $23.4 \mathrm{kcal} / \mathrm{mol} .^{27}$ Therefore, initiation is significantly slower than carbene exchange. During the decomposition process, only a small portion of the catalyst will be initiated to 9 and then the remaining vinyl ether will react rapidly with 9, epimerizing the complex to 18 (leading to hydride 15). This final step regenerates 1 equiv of vinyl ether, leading to net consumption of 1 equiv of vinyl ether per equivalent of catalyst in the decomposition process. The rapid epimerization of $\mathbf{9}$ to $\mathbf{1 8}$ also explains why we do not observe two Fischer carbene isomers experimentally. While 9 and 18 are in rapid equilibrium, $\mathbf{1 8}$ is predicted to be heavily favored $\left(>98 \%\right.$ at room temperature).$^{21}$

In conclusion, we have demonstrated that Fischer carbenes are formed from reactions of vinyl ethers with cyclometalated $Z$-selective ruthenium metathesis catalysts. These Fischer carbenes degrade to ruthenium hydrides rapidly under the reaction conditions, as identified by ${ }^{1} \mathrm{H}$ NMR experiments. Using DFT, we have also shown that Fischer carbenes such as $\mathbf{9}$ and $\mathbf{1 8}$ are not metathesis inactive if carbenes of similar stability result. These results have an important effect for the future use of vinyl ethers to quench reactions involving cyclometalated $Z$-selective catalysts. When vinyl ethers are used to quench a metathesis reaction, ruthenium hydrides can form rapidly in the reaction mixture if the Fischer carbene is not separated promptly. The presence of hydrides can potentially lead to degradation of the $Z$-olefin content or olefin walking. Experiments to determine how these hydrides affect internal olefins are currently underway.

\section{ASSOCIATED CONTENT}

\section{S Supporting Information}

The Supporting Information is available free of charge on the ACS Publications website at DOI: 10.1021/acs.organomet.8b00150.

Experimental procedures, detailed NMR studies, computational details, and energies of computed structures (PDF)

Coordinates of all computed species (optimized at the B3LYP level) (XYZ)

\section{AUTHOR INFORMATION}

\section{Corresponding Authors}

*E-mail for K.N.H.: houk@chem.ucla.edu.

*E-mail for R.H.G.: rhg@caltech.edu.

\section{ORCID}

Jessica M. Grandner: 0000-0001-5068-8665

K. N. Houk: 0000-0002-8387-5261

Robert H. Grubbs: 0000-0002-0057-7817

\section{Author Contributions}

${ }^{\S}$ T.S.A. and J.M.G. contributed equally to this work. Ahmed performed the majority of experiments and Grandner performed all computations.

\section{Notes}

The authors declare no competing financial interest.

\section{ACKNOWLEDGMENTS}

The research described was financially supported by the NSF (CHE-1502616), NIH (GM031332), and ONR (N000141310895 and N00014-14-1-0650). Calculations were performed using the NSF funded (OCI-1053575) Extreme Science and Engineering Discovery Environment (XSEDE), the UCLA IDRE Hoffman2 Cluster, and the ONR supported Copper Cluster. T.S.A. is grateful for support from the National Science Foundation through a Graduate Research Fellowship. D. VanderVelde is acknowledged for his assistance with NMR experiments. B. L. Quigley is thanked for helpful discussions. Materia, Inc. is thanked for generous donations of catalysts 3 and 4 .

\section{REFERENCES}

(1) Schrodi, Y.; Ung, T.; Vargas, A.; Mkrtumyan, G.; Lee, C. W.; Champagne, T. M.; Pederson, R. L.; Hong, S. H. Clean: Soil, Air, Water 2008, 36, 669-673.

(2) Grubbs, R. H.; O'Leary, D. J. Handbook of Metathesis, 2nd ed.; Wiley-VCH: Weinheim, Germany, 2015; Vol. 2 (Applications in Organic Synthesis).

(3) (a) Slugovc, C. Macromol. Rapid Commun. 2004, 25, 12831297. (b) Miyake, G. M.; Piunova, V. A.; Weitekamp, R. A.; Grubbs, R. H. Angew. Chem., Int. Ed. 2012, 51, 11246-11248.

(4) Cossy, J.; Arseniyadis, S.; Meyer, C. Metathesis in Natural Product Synthesis: Strategies, Substrates and Catalysts; Wiley-VCH: Weinheim, Germany, 2011.

(5) Trnka, T. M.; Grubbs, R. H. Acc. Chem. Res. 2001, 34, 18-29.

(6) For examples see: (a) Maynard, H. D.; Grubbs, R. H. Macromolecules 1999, 32, 6917-6924. (b) Quigley, B. L.; Grubbs, R. H. Chem. Sci. 2014, 5, 501-506. (c) Ahmed, T. S.; Grubbs, R. H. J. Am. Chem. Soc. 2017, 139, 1532-1537. (d) Ahmed, T. S.; Grubbs, R. H. Angew. Chem., Int. Ed. 2017, 56, 11213-11216.

(7) Sanford, M. S.; Love, J. A.; Grubbs, R. H. J. Am. Chem. Soc. 2001, $123,6543-6554$.

(8) Vorfalt, T.; Wannowius, K.-J.; Plenio, H. Angew. Chem., Int. Ed. 2010, 49, 5533-5536.

(9) Louie, J.; Grubbs, R. H. Organometallics 2002, 21, 2153-2164.

(10) Takahira, Y.; Morizawa, Y. J. Am. Chem. Soc. 2015, 137, 70317034.

(11) Endo, K.; Grubbs, R. H. J. Am. Chem. Soc. 2011, 133, 85258527.

(12) Keitz, B. K.; Endo, K.; Patel, P. R.; Herbert, M. B.; Grubbs, R. H. J. Am. Chem. Soc. 2012, 134, 693-699.

(13) Rosebrugh, L. E.; Herbert, M. B.; Marx, V. M.; Keitz, B. K.; Grubbs, R. H. J. Am. Chem. Soc. 2013, 135, 1276-1279.

(14) Liu, P.; Xu, X.; Dong, X.; Keitz, B. K.; Herbert, M. B.; Grubbs, R. H.; Houk, K. N. J. Am. Chem. Soc. 2012, 134, 1464-1467.

(15) Herbert, M. B.; Lan, Y.; Keitz, B. K.; Liu, P.; Endo, K.; Day, M. W.; Houk, K. N.; Grubbs, R. H. J. Am. Chem. Soc. 2012, 134, 78617866.

(16) See the Supporting Information of this reference for a recent example: Hartung, J.; Dornan, P. K.; Grubbs, R. H. J. Am. Chem. Soc. 2014, 136, 13029-13037.

(17) (a) Courchay, F. C.; Sworen, J. C.; Ghiviriga, I.; Abboud, K. A.; Wagener, K. B. Organometallics 2006, 25, 6074-6086. (b) Rowley, C. N.; Foucault, H. M.; Woo, T. K.; Fogg, D. E. Organometallics 2008, 27, 1661-1663. (c) Ashworth, I. W.; Hillier, I. H.; Nelson, D. J.; Percy, J. M.; Vincent, M. A. Eur. J. Org. Chem. 2012, 2012, 56735677. (d) Clark, J. R.; Griffiths, J. R.; Diver, S. T. J. Am. Chem. Soc. 2013, 135, 3327-3330.

(18) This observation is consistent with studies of previously reported Fischer carbenes.'

(19) Shifts are consistent with those of other $\mathrm{Ru}-\mathrm{H}$ complexes. ${ }^{15}$ 
(20) Attempts at isolation of these complexes resulted in decomposition of the observed species.

(21) Conducting this reaction at $0{ }^{\circ} \mathrm{C}$ allows for the observation of a very minor signal at $13.57 \mathrm{ppm}(<2 \%$ with respect to the signal at $13.83 \mathrm{ppm}$ ) in the ${ }^{1} \mathrm{H}$ NMR spectrum, which may belong to another isomer of the Fischer carbene.

(22) To further confirm this absence, no correlations to this region were observed in the ${ }^{1} \mathrm{H}-{ }^{13} \mathrm{C}$ HMBC spectrum.

(23) For typical $\mathrm{Ru}=\mathrm{C}{ }^{13} \mathrm{C}$ NMR shifts, see ref 15.

(24) Reference 14 discusses the direct epimerization of the ruthenium center via reorientation of the alkylidene in the Supporting Information. Intermediates along this pathway were substantially higher in energy than metathesis via our computed pathway.

(25) Dang, Y.; Wang, Z.-X.; Wang, X. Organometallics 2012, 31, 8654-8657.

(26) Decomposition of $\mathbf{1 8}^{\prime}$ is shown in Figure S18 of the Supporting Information.

(27) See Figure S19 in the Supporting Information for a diagram. 